\title{
Necessity for subsequent surgery in women of child-bearing age with positive margins after conization
}

Xinmei Wang ${ }^{1,2} \mathbb{D}$, Juan $\mathrm{Xu}^{1}$, Yang Gao ${ }^{1}$ and Pengpeng $\mathrm{Qu}^{2^{*}}$

\begin{abstract}
Background: $20-25 \%$ of women with high-grade cervical intraepithelial neoplasias (HSIL) have residual lesions after conization. The state of the margin is generally considered to be a risk factor for recurrence or persistent lesions. Predictors of positive margins and residual lesions need to be identified. A design for postoperative management and avoidance of overtreatment needs to be provided, especially for women of child-bearing age.

Methods: This study was a retrospective analysis of 1309 women of child-bearing age with HSIL, who underwent cold knife conization (CKC). Age, gravidity, parity, human papillomavirus (HPV) species, cytology, transformation zone type, results of endocervical curettage (ECC), quadrant involvement, glandular involvement, and Cervical Intraepithelial Neoplasia (CIN) grade were analyzed. Among those with positive margins, 245 patients underwent secondary surgery within three months, including CKC, a loop electrosurgical excision procedure, and total hysterectomy. Risk factors for positive margins and residual lesions were assessed.
\end{abstract}

Results: There was no significant difference in age, gravidity, parity, glandular involvement, and CIN grade between the two groups $(P>0.3)$. There was a significant difference in HPV species, cytology, ECC results, and quadrant involvement $(P<0.002)$. Multivariate analysis showed a major cytology abnormality, high-risk HPV infection, type III transformation zone, positive ECC result, and multiple quadrant involvement were independent risk factors for positive margins and residual lesions $(P<0.02)$. Age $>35$ years was also a risk factor for residual lesions $(P<0.03)$.

Conclusion: High-risk women should be treated appropriately considering fertility. Patients with positive margins should be managed uniquely. Surgery for women without fertility may be appropriate. Close follow-up is necessary for women who have fertility requirements or are unwilling to undergo subsequent surgery if they have no risk factors, especially women $<35$ years.

Keywords: Cervical intraepithelial neoplasia (CIN), Women of child-bearing age, Cold knife conization (CKC), Positive margins, Residual lesions, High-risk HPV

\section{Background}

In 2015, the American Society of Colposcopy and Cervical Pathology (ASCCP) recommended that one of

\footnotetext{
*Correspondence: qu.pengpeng@hotmail.com

${ }^{2}$ Department of Gynecological Oncology, Tianjin Central Hospital of Gynecology and Obstetrics, Tianjin 300100, China

Full list of author information is available at the end of the article
}

the standard treatment options for cervical squamous intraepithelial lesions (SIL), especially HSIL [including CIN3 and part of CIN2], was cervical conization [1], including LEEP and CKC. However, these two types of conization have a common limitation; that is, $20-25 \%$ of women have residual lesions after an operation [2]. The state of the margin is generally considered to be a risk factor for recurrence or persistent CIN [3, 4].A 
comprehensive meta-analysis by Debeaudrap revealed that the rate of positive margins after conization was about $23.0 \%(8091 / 35,109)$ [5].

With improvement of people's awareness of health care and advances in detection technology, the age of onset for this disease is becoming increasingly younger. Furthermore, due to changes in China's family planning policy in recent years, an increasing number of women of childbearing age have fertility requirements. Although hysterectomy is the definitive therapy for women with positive margins who have no reproductive requirements, cervical conization is considered an acceptable alternative in women who desire fertility preservation. There have been conflicting reports regarding recurrence rates and residual disease in women undergoing cervical conization for CIN $[2,4,5]$. Moreover, secondary conization can affect conception and lead to adverse pregnancy outcomes $[6$, 7]. Therefore, the ideal management of women of childbearing age with positive margins remains controversial.

In order to get the management model of women of child-bearing age with positive margins, the clinicopathological data of 1309 women of child-bearing age with high-grade CIN (including CIN3 and CIN2) and 245 cases with positive margins who underwent subsequent surgery within three months was analyzed, and the risk factors of positive margins and residual lesions were explored. The purpose of our study was to guide the postoperative management of this group of women.

\section{Methods}

\section{Clinical data}

Case inclusion criteria were women of child-bearing age who had been diagnosed with HSIL by biopsy, including CIN3 and part of CIN2. All women were premenopausal women. Case exclusion criteria were women with complications, such as endometrial carcinomas; cervical cancer including micro-invasion; incomplete information, such as lacking correlations among cytology, biopsy, and colposcopic findings; and no contact information.

A total of 1309 women of child-bearing age with HSIL (including CIN3 and part of CIN2) in Tianjin Central Hospital of Gynecology and Obstetrics from January 2013 to December 2019, aged from 20 to 49 years old, were diagnosed with a "three-step" method, including cytology, colposcopy, and histology [8]. All women were premenopausal women. And all women underwent CKC. According to the state of the margin of specimens, they were divided into two groups: (1) positive group: women with positive margins (321, 24.52\%); and (2) negative group: women with negative margins (988, 75.48\%). Among them, 245 women underwent subsequent surgery within three months. Age, gravidity, parity, HPV species, cytology, transformation zone type, the results of endocervical curettage (ECC), quadrant involvement, glandular involvement, and CIN grade were recorded (Fig. 1). The data were collected from the electronic medical records of the institution while preserving patient anonymity. The research ethics committee waived the requirement for ethical approval and informed consent because the study used previously stored data.

\section{Criteria for positive margins and residual lesions}

If HSIL were found in the resection margin of about $1 \mathrm{~mm}$ or less, including the ectocervical margin, endocervical margin, or both, it was regarded as a positive margin. If HSIL were diagnosed in women who underwent secondary surgery within three months, it was assumed to be a residual lesion. CIN1 was not considered to be a residual lesion in this study.

\section{Statistical methods}

SPSS21.0 software was used for statistical analysis (SPSS Inc, Chicago, IL, USA). The statistical methods were examination of exact probabilities in a fourfold table and chi-squared tests. Multivariate analysis was performed using a logistic regression model. All tests were twosided, and the level of significance was set at $P<0.05$.

\section{Results}

The average age of women was $38 \pm 7.1$ (range 20-49) years. According to the state of the margin of specimens, they were divided into two groups: (1) positive group: women with positive margins (321, 24.52\%); and (2) negative group: women with negative margins $(988,75.48 \%)$. In women with positive margins, 245 cases underwent subsequent surgery within three months, including secondary CKC, LEEP, and total hysterectomy.

\section{Association between clinicopathological factors and positive margins}

Women in both groups were divided into two levels, depending on age gravidity, parity, HPV species, cytology, transformation zone type, the results of ECC, quadrant involvement, glandular involvement, and CIN grade. There was no significant difference in age, gravidity, and parity between the two groups $(P>0.3)$. The high-risk HPV (HR-HPV) infection rate in the positive group was significantly higher than in the negative group $(P<0.001)$. The preoperative cytology results in the positive group were mainly HSIL and high-grade squamous intraepithelial lesions (ASC-H). These results were significantly different from that in the negative group $(P<0.001)$.In the negative group, the preoperative cytology results were mainly intraepithelial lesion or malignancy (NILM) and atypical squamous cells undetermined significance (ASCUS). The primary 


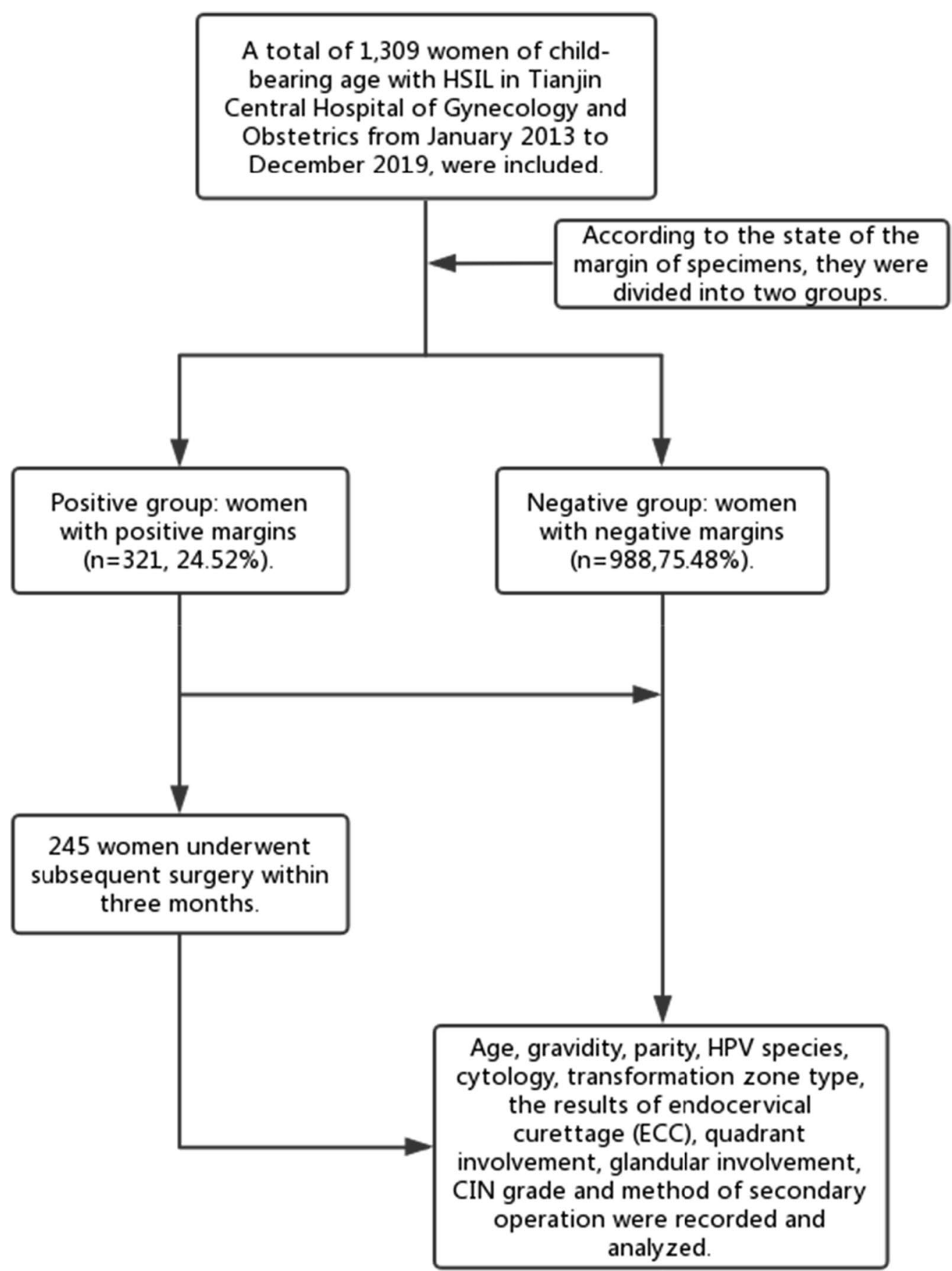

Fig. 1 Flow chart

type of transformation zone in the positive group was type III (61.08\%), while the proportion of type III in the negative group was only $38.92 \%$.There was a significant difference in the transformation zone type between the two groups $(P<0.001)$. There was also a significant difference in the results of ECC between the two groups $(P=0.002)$. There was no significant difference in the percentage of women with glandular involvement and CIN grade between the two groups $(P>0.3)$. Multiple quadrant involvement was more frequently found in the 
Table 1 Association between clinicopathological factors and positive margins

\begin{tabular}{|c|c|c|c|c|}
\hline Characteristics & $\begin{array}{l}\text { Positive } \\
(n=321)\end{array}$ & $\begin{array}{l}\text { Negative } \\
(n=988)\end{array}$ & Chi-squared & $P$ value \\
\hline \multicolumn{5}{|l|}{ Age (years) } \\
\hline$\leq 35$ & $23.02(102 / 443)$ & $76.98(341 / 443)$ & 0.812 & 0.368 \\
\hline$>35$ & $25.29(219 / 866)$ & $74.71(647 / 866)$ & & \\
\hline \multicolumn{5}{|l|}{ Gravidity } \\
\hline$\leq 3$ & $25.96(135 / 520)$ & $74.04(385 / 520)$ & 0.965 & 0.326 \\
\hline$>3$ & 23.57(186/789) & $76.43(603 / 789)$ & & \\
\hline \multicolumn{5}{|l|}{ Parity } \\
\hline$\leq 2$ & 23.84(201/843) & $76.16(642 / 843)$ & 0.590 & 0.442 \\
\hline$>2$ & $25.75(120 / 466)$ & $74.24(346 / 466)$ & & \\
\hline \multicolumn{5}{|l|}{ Cytology } \\
\hline Minor abnormalities & $12.06(55 / 456)$ & $87.94(401 / 456)$ & 58.707 & $<0.001$ \\
\hline Major abnormalities & $31.18(266 / 853)$ & 68.82((587/853) & & \\
\hline \multicolumn{5}{|l|}{ High-risk HPV } \\
\hline Yes & $31.42(268 / 853)$ & $68.58(585 / 853)$ & 62.912 & $<0.001$ \\
\hline No & $11.62(53 / 456)$ & $88.38(403 / 456)$ & & \\
\hline \multicolumn{5}{|l|}{ Transformation zone } \\
\hline I and || & $11.08(106 / 957)$ & $88.92(851 / 957)$ & 347.6 & $<0.001$ \\
\hline III & $61.08(215 / 352)$ & $38.92(137 / 352)$ & & \\
\hline \multicolumn{5}{|l|}{ ECC } \\
\hline Positive & $39.50(188 / 476)$ & $60.50(288 / 476)$ & 9.594 & 0.002 \\
\hline Negative & $15.97(133 / 833)$ & $84.03(700 / 833)$ & & \\
\hline \multicolumn{5}{|l|}{ Quadrant involvement } \\
\hline Single & $12.01(73 / 608)$ & $87.99(535 / 608)$ & 96.088 & $<0.001$ \\
\hline Multiple & $35.38(248 / 701)$ & $64.62(453 / 701)$ & & \\
\hline \multicolumn{5}{|l|}{ Glandular involvement } \\
\hline Yes & 23.83(194/814) & $76.17(620 / 814)$ & 0.533 & 0.457 \\
\hline No & $25.66(127 / 495)$ & $74.34(368 / 495)$ & & \\
\hline \multicolumn{5}{|l|}{ CIN grade } \\
\hline CIN2 & 26.42(79/299) & $73.58(220 / 299)$ & 0.755 & 0.385 \\
\hline CIN3 & $23.96(242 / 1010)$ & 76.04(768/1010) & & \\
\hline
\end{tabular}

Minor abnormalities included NILM (negative for intraepithelial lesion or malignancy), ASCUS (atypical squamous cells of undetermined significance), and LSIL (lowgrade squamous intraepithelial lesion); major abnormalities included ASC-H (atypical squamous cells, cannot exclude high-grade squamous intraepithelial lesion) and HSIL (high-grade squamous intraepithelial lesion)

positive margin group, which was significantly different from that in the negative group $(P<0.001$; Table 1$)$.

\section{Logistic regression analysis of the risk factors for positive margins}

In order to evaluate which variables could be considered as independent predictors for positive margins after conization, we used Logistic regression analysis. It was found that major cytology abnormality, HR-HPV infection, type III transformation zone, positive ECC result, and multiple quadrant involvement were independent risk factors for the positive margins $(P<0.02$; Table 2$)$.

\section{Univariate and multivariate analyses of risk factors for residual lesions in women with positive margins}

In women with positive margins, 245 cases underwent subsequent surgery within three months, and of them, 93 cases received hysterectomy, 152 cases chose secondary conization (70 cases in LEEP and 82 cases in CKC). 83 cases $(33.88 \%)$ had residual lesions detected in the postoperative specimens. Univariate analysis showed that age $>35$ years, the severity of cytology results, high-risk HPV infection, type of transformation zone, the ECC result, and quadrant involvement were associated with residual lesions of the women with positive margins after CKC $(P<0.05)$. In a multivariate analysis, age $>35$ years, a major cytology abnormality (including HSIL and 
Table 2 Logistic regression analysis of the risk factors for positive margins

\begin{tabular}{lllccrr}
\hline Variables & B & SE & Wald & $P$ value & OR & OR (95\% Cl) \\
\hline Cytology & 1.161 & 0.427 & 13.879 & $<0.001$ & 2.614 & $2.241-4.249$ \\
High-risk HPV & 1.198 & 0.254 & 15.129 & $<0.001$ & 3.612 & $2.388-5.997$ \\
Transformation zone & 0.912 & 0.138 & 8.268 & 0.001 & 1.825 & $1.675-3.111$ \\
ECC & 0.685 & 0.612 & 5.308 & 0.008 & 1.744 & $1.187-3.146$ \\
Quadrant involvement & 1.032 & 0.423 & 5.714 & 0.011 & 1.620 & $1.366-2.124$ \\
\hline
\end{tabular}

Table 3 Univariate and multivariate analysis of risk factors for residual lesions in women with positive margins

\begin{tabular}{|c|c|c|c|c|}
\hline \multirow[t]{2}{*}{ Variable } & \multirow[t]{2}{*}{ Residual rate (\%) } & \multirow{2}{*}{$\begin{array}{l}\text { Univariate } \\
P \text { value }\end{array}$} & \multicolumn{2}{|l|}{ Multivariate } \\
\hline & & & OR $(95 \% \mathrm{Cl})$ & $P$ value \\
\hline \multicolumn{5}{|l|}{ Age(years) } \\
\hline$\leq 35$ & $24.39(20 / 82)$ & 0.026 & $1.429(1.056-2.968)$ & 0.037 \\
\hline$>35$ & $38.65(63 / 163)$ & & & \\
\hline \multicolumn{5}{|l|}{ Gravidity } \\
\hline$\leq 3$ & $33.70(31 / 92)$ & 0.507 & Variable removed & \\
\hline$>3$ & $33.99(52 / 153)$ & & & \\
\hline \multicolumn{5}{|l|}{ Parity } \\
\hline$\leq 2$ & $30.30(40 / 132)$ & 0.428 & Variable removed & \\
\hline$>2$ & $38.05(43 / 113)$ & & & \\
\hline \multicolumn{5}{|l|}{ Cytology } \\
\hline Minor abnormalities & $15.19(12 / 79)$ & $<0.001$ & $3.143(1.986-5.113)$ & $<0.001$ \\
\hline Major abnormalities & $42.77(71 / 166)$ & & & \\
\hline \multicolumn{5}{|l|}{ High-risk HPV } \\
\hline Yes & 44.59(33/74) & 0.020 & $1.483(1.345-3.226)$ & 0.029 \\
\hline No & $29.24(50 / 171)$ & & & \\
\hline \multicolumn{5}{|l|}{ Transformation zone } \\
\hline | and || & 25.32(39/154) & $<0.001$ & $2.996(1.636-4.825)$ & 0.001 \\
\hline III & 48.35(44/91) & & & \\
\hline \multicolumn{5}{|l|}{ ECC } \\
\hline Positive & 45.88(39/85) & 0.005 & $2.127(1.118-2.970)$ & 0.007 \\
\hline Negative & $27.50(44 / 160)$ & & & \\
\hline \multicolumn{5}{|l|}{ Quadrant involvement } \\
\hline Single & $25.19(33 / 131)$ & 0.003 & $1.824(1.441-2.609)$ & 0.004 \\
\hline Multiple & $43.86(50 / 114)$ & & & \\
\hline \multicolumn{5}{|l|}{ Glandular involvement } \\
\hline No & $32.82(43 / 131)$ & 0.636 & Variable removed & \\
\hline Yes & $35.09(40 / 114)$ & & & \\
\hline \multicolumn{5}{|l|}{ CIN grade } \\
\hline CIN2 & $30.19(32 / 106)$ & 0.251 & Variable removed & \\
\hline CIN3 & $36.69(51 / 139)$ & & & \\
\hline \multicolumn{5}{|c|}{ Site of margin involvement } \\
\hline Endo & $33.33(25 / 75)$ & 0.866 & Variable removed & \\
\hline Ecto & $32.35(33 / 102)$ & & & \\
\hline Endo/Ecto & $36.76(25 / 68)$ & & & \\
\hline \multicolumn{5}{|c|}{ Method of secondary operation } \\
\hline CKC & $29.27(24 / 82)$ & 0.349 & Variable removed & \\
\hline Total hysterectomy & $38.70(36 / 93)$ & & & \\
\hline LEEP & $32.86(23 / 70)$ & & & \\
\hline
\end{tabular}


ASC-H), high-risk HPV infection, type III transformation zone, positive ECC result, and multiple quadrant involvement were all risk factors for residual lesions $(P<0.05$; Table 3).

\section{Discussion}

Cervical conization is the preferred method for the diagnosis and treatment of CIN. CKC is one type of cervical conization. Because CIN lesions are often multipoint in distribution, residual lesions and positive margins are inevitable. Studies have indicated that the incidence of residual lesions in women with positive margins after cervical conization was higher than that in women with negative margins, and the recurrence rate of women with positive margins was also higher in women with positive margins $[9,10]$. It has been reported in the literature that the incidence of positive margins after cervical conization was $14-25 \%$ $[2,9,10]$.which was similar to our study.However, the rate of residual lesions $(33.38 \%)$ in our study was higher than in a previous study $[11,12]$.This may be due to the clinical characteristics of the population who chose subsequent surgeries. In recent years, the onset age of this disease has been increasingly younger. However, there is no unified clinical opinion on the risk factors and further treatment for the women of child-bearing age with positive margins. In women with no fertility requirements, considering the possibility of a poor prognosis, total hysterectomy may be possible. However, for women of child-bearing age who have fertility requirements or want to retain the uterus, it is almost impossible to accept the uterus being removed. Even secondary conization can affect conception and lead to adverse pregnancy outcomes $[6,7]$.Therefore, avoiding a positive margin and residual lesions, and reducing unnecessary secondary surgery are particularly important for women of childbearing age.

The results of previous studies have suggested that the possible risk factors for residual lesions after cervical conization mainly include positive margins of the specimen, involvement of the lateral margin of the cervical canal, involvement of the lateral margin of the cervical canal and outer orifice, positive specimen from ECC, menopause, persistent infection of high-risk HPV after cervical conization, and decreased or suppressed immune function [13, 14]. Many factors affect the condition of the margin after $\mathrm{CKC}$, including age, menopausal status, glandular involvement, smoking, infection, training level of the operator, and other factors $[15,16]$. In this study, the clinicopathological characteristics of 1309 women of child-bearing age after initial CKC and 245 cases of women with positive margins who accepted subsequent surgery within three months were retrospectively analyzed. It was found that a major cytology abnormality (including HSIL and ASC-H), HR-HPV infection type III transformation zone, positive ECC result, and multiple quadrant involvement were the common risk factors for positive margins and residual lesions. Age $>35$ years was also a risk factor for residual lesions in women with positive margins after initial CKC.

Whether the severity of a cytological abnormality is related to positive margins has been long disputed by researchers. Ryu A reported that the cytologic grade before cervical conization was not a risk factor for residual disease or recurrence [17]. However, Ayhan showed that the result of a smear was an advantageous predictor for a positive ectocervical margin, and it was associated with a decrease in the occurrence rate of positive margins and residual lesions [18]. In this study, the women with major cytology abnormalities (including ASC-Hs and HSIL) were more likely to present with positive margins and residual lesions than women with minor cytology abnormalities (including NILM, ASCUS, and LSIL) before CKC,which was consistent with previous researches $[17,18]$. It was found that the severity of cytology before conization was a risk factor for positive margins and residual lesions in this study. With an increase in the cytological grade, CIN levels increased, which meant that the depth of the lesion cells occupying the squamous epithelium increased, and the possibility of positive margins and residual lesions increased.

High-risk HPV infection has been recognized as a necessary condition for the occurrence and development of cervical squamous epithelial lesions and cervical cancer [19]. In this study, the rate of high-risk HPV infection in women with positive margins after CKC was $83.50 \%$ (268/321). Multivariate analysis showed that a high-risk HPV infection was the independent risk factor for positive margins and residual lesions, which was consistent with previous study $[20,21]$. However, at present, the pathological mechanism for a high rate of positive margins and residual lesions after cervical conization caused by high-risk HPV infection is not very clear; it may due to the cervical lesion area in women with CIN infected by high-risk HPV was larger and deeper than that of women infected by low-risk HPV [22]. Giorgio Bogani also reported that HR-HPV-negative high-grade cervical dysplasia experience more favorable outcomes than patients with documented HR-HPV infection(s) [23].

Further study is needed. Based on the above studies, the HPV type can better predict postoperative positive margins and residual lesions.

In addition, it was also found that women with a type III transformation zone were more likely to have positive margins and residual lesions after an operation. This may be due to the lesion invading the cervical tube. CKC 
cannot completely remove diseased tissue. In the same way, the rates for positive margins and residual lesions in women with positive results of ECC were higher than that of negative results. The same results were found in previous studies [23, 24]. Researchers also found that multiple quadrant involvement was a risk factor for positive margins and residual lesions [25, 26]. It came to the same conclusion based on our foundings. In this study, the rate of multiple quadrant involvement was $77.26 \%$ in the women with positive margins, and that in the women with negative margins was $45.85 \%$. Increases in the range of lesions likely affected observations during the operation, interfered with the judgment of surgical margins, and increased the difficulty of surgery. The above factors should be taken into account in the process of cervical conization to achieve the goal of leaving no residual lesions and preserving cervical function to a greater extent, that is, more attention should be paid to the extent and depth of lesions removed by cervical conization.

There was no significant difference between women of age $>35$ years and $\leq 35$ years in the rate of positive margins, but there was a significant difference in the rate of residual lesions between the two age groups. The rate of residual lesions in the age $>35$ years group was higher than the $\leq 35$ years group $(P<0.03)$. This may be due to the persistent infection of HPV, especially high-risk HPV. Sarian reported that women older than 35 years had a significantly higher risk for persistent infection following LEEP [27]. This could cause multiple quadrant lesions of the cervix [22]. Furthermore, the older the patient, the higher the degree of cervical atrophy. The cervical transformation zone and lesions therefore moved inward to the cervical canal, so cervical conization could not completely remove the diseased tissue. Bilibio also considered that increasing age was the only factor that accurately predicted residual disease [15]. All of these results indicated older age was a predictive factor for residual lesions and it can play a better role in guiding the formulation of a postoperative treatment plan for women of childbearing age with positive margins. Subsequently, normal reproductive function and organ integrity can be preserved as much as possible in women younger than 35 years old.

\section{Conclusion}

Our study's main strength was the particular group of patients we included: women of child-bearing age. This group of patients has the strongest desire to preserve reproductive function or uterus and the postoperative treatment of positive margins after CKC is faced with more challenges. Besides, patients with positive margins who underwent the secondary surgery were from the same sample group, reducing bias and achieving more accurate results.

However, this study also had unavoidable limitations of its retrospective design. First, we could not assess all variables potentially associated with residual lesions in the single study. Furthermore, the cases involving only one hospital might have reduced our results' external validity, and further prospective studies with a larger sample size in a broader context are needed. Additionally, the women in our cohort were tested for HPV and TCT, which largely determined subsequent treatment. However, from the analysis results of residual lesions, it could be seen that there are still a large number of people who can avoid secondary surgery, which requires more accurate biomarkers to reduce the rate of secondary surgery [28-30].

In conclusion, a major cytology abnormality (including HSIL and ASC-H), HR-HPV infection, III transformation zone, positive ECC result, and multiple quadrant involvement were the common risk factors for positive margins and residual lesions. Age $>35$ years was also a risk factor for residual lesions in women with positive margins after initial CKC. Experienced doctors should treat these highrisk women appropriately, operate prudently, and expand the scope of the operation while considering the patient's fertility requirements. Furthermore, the patient with positive margins after CKC should be managed individually. It is reasonable to require further surgical treatment in women without fertility requirement, and close followup is necessary for women who have fertility requirements or are unwilling to undergo subsequent surgery if they have no risk factor, especially for women $<35$ years.

\section{Abbreviations}

HSIL: High grade cervical intraepithelial lesions; HPV: Human papillomavirus; HR-HPV: High-risk human papillomavirus; CIN: Cervical intraepithelial neoplasia; CKC: Cold knife conization; ECC: Endocervical curettage; TCT: Thin prep cytologic test; LEEP: Loop electrosurgical excisional procedure; NILM: Negative for intraepithelial lesion or malignancy; LSIL: Low grade cervical intraepithelial lesions; HSIL: High grade cervical intraepithelial lesions; ASCUS: Atypical squamous cells of undetermined significance; ASC-H: Atypical squamous cells, cannot exclude high-grade squamous intraepithelial lesion.

\section{Acknowledgements}

We thank all participants in the study for their invaluable contribution.

Authors' contributions

XmW: Project development, Data Collection, Manuscript writing. JX: Data collection and Data analysis. YG: Data collection and Data analysis. PpQ: Project development. All authors have read and approved the final manuscript.

\section{Funding}

The project name: Establishment and clinical application of early diagnosis system for cervical precancerous lesions caused by HPV E6 and E7. Contract no.: 19YFZCSY00600.

Availability of data and materials Not applicable. 


\section{Declarations}

\section{Ethics approval and consent to participate}

This retrospective analysis was exempt from ethics committee approval at Tianjin Medical University, Tianjin Central Hospital of Gynecology and Obstetrics, because the committee did not consider approval was necessary for a retrospective chart review. The data were collected through the electronic medical records of the institution while preserving patient anonymity, and the research ethics committee waived the requirement for informed consent because the study used previously stored data. Administrative permissions were not required to access and use the medical records described in our study.

\section{Consent to publish}

Not applicable.

\section{Competing interests}

The authors declare that they have no competing interests.

\section{Author details}

'Clinical College of Central Gynecology and Obstetrics, Tianjin Medical University, Tianjin 300070, China. ${ }^{2}$ Department of Gynecological Oncology, Tianjin Central Hospital of Gynecology and Obstetrics, Tianjin 300100, China.

Received: 3 January 2021 Accepted: 22 April 2021

Published online: 07 May 2021

\section{References}

1. Darragh TM, Colgan TJ, Thomas Cox J, Heller DS, Henry MR, Luff RD, McCaImont T, Nayar R, Palefsky JM, Stoler MH, Wilkinson EJ, Zaino RJ, Wilbur DC; Members of the LAST Project Work Groups. The lower anogenital squamous terminology standardization project for HPV-associated lesions: background and consensus recommendations from the College of American Pathologists and the American Society for Colposcopy and Cervical Pathology. Int J Gynecol Pathol. 2013;32(1):76-115. https:// doi.org/10.1097/PGP.0b013e31826916c7. Erratum in: Int J Gynecol Pathol. 2013 Jul;32(4):432. Erratum in: Int J Gynecol Pathol. 2013 Mar;32(2):241

2. Arbyn M, Redman CWE, Verdoodt F, Kyrgiou M, Tzafetas M, GhaemMaghami S, Petry KU, Leeson S, Bergeron C, Nieminen P, Gondry J, Reich $\mathrm{O}$, Moss EL. Incomplete excision of cervical precancer as a predictor of treatment failure: a systematic review and meta-analysis. Lancet Oncol. 2017;18(12):1665-79. https://doi.org/10.1016/S1470-2045(17)30700-3.

3. Kietpeerakool C, Khunamornpong S, Srisomboon J, Siriaunkgul S, Suprasert P. Cervical intraepithelial neoplasia II-III with endocervical cone margin involvement after cervical loop conization: is there any predictor for residual disease? J Obstet Gynaecol Res. 2007;33(5):660-4. https://doi. org/10.1111/j.1447-0756.2007.00628.x.

4. Park JY, Lee SM, Yoo CW, Kang S, Park SY, Seo SS. Risk factors predicting residual disease in subsequent hysterectomy following conization for cervical intraepithelial neoplasia (CIN) III and microinvasive cervical cancer. Gynecol Oncol. 2007;107(1):39-44. https://doi.org/10.1016/j.ygyno.2007. 05.014

5. Debeaudrap P, Sobngwi J, Tebeu PM, Clifford GM. Residual or recurrent precancerous lesions after treatment of cervical lesions in human immunodeficiency virus-infected women: a systematic review and metaanalysis of treatment failure. Clin Infect Dis. 2019;69(9):1555-65. https:// doi.org/10.1093/cid/ciy1123.

6. Pils S, Eppel W, Seemann R, Natter C, Ott J. Sequential cervical length screening in pregnancies after loop excision of the transformation zone conisation: a retrospective analysis. BJOG. 2014;121(4):457-62. https://doi. org/10.1111/1471-0528.12390.

7. Sozen H, Namazov A, Cakir S, Akdemir Y, Vatansever D, Karateke A. Pregnancy outcomes after cold knife conization related to excised cone dimensions. A retrospective cohort study. J Reprod Med. 2014:59(1-2):81-6.
8. Coccia PF, Pappo AS, Beaupin L, et al. Adolescent and young adult oncology, version 2.2018, NCCN clinical practice guidelines in oncology. J Natl Compr Canc Netw. 2018;16:66-97.

9. Fu Y, Chen C, Feng S, Cheng X, Wang X, Xie X, Lü W. Residual disease and risk factors in patients with high-grade cervical intraepithelial neoplasia and positive margins after initial conization. Ther Clin Risk Manag. 2015;11:851-6. https://doi.org/10.2147/TCRM.S81802.

10. Chen JY, Wang ZL, Wang ZY, Yang XS. The risk factors of residual lesions and recurrence of the high-grade cervical intraepithelial lesions (HSIL) patients with positive-margin after conization. Medicine (Baltimore). 2018;97(41):e12792. https://doi.org/10.1097/MD.0000000000012792.

11. Kocken M, Helmerhorst TJ, Berkhof J, Louwers JA, Nobbenhuis MA, Bais AG, Hogewoning CJ, Zaal A, Verheijen RH, Snijders PJ, Meijer CJ. Risk of recurrent high-grade cervical intraepithelial neoplasia after successful treatment: a long-term multi-cohort study. Lancet Oncol. 2011;12(5):44150. https://doi.org/10.1016/S1470-2045(11)70078-X.

12. Serati M, Siesto G, Carollo S, Formenti G, Riva C, Cromi A, Ghezzi F. Risk factors for cervical intraepithelial neoplasia recurrence after conization: a 10-year study. Eur J Obstet Gynecol Reprod Biol. 2012;165(1):86-90. https://doi.org/10.1016/j.ejogrb.2012.06.026.

13. Ruano Y, Torrents M, Ferrer FJ. Human papillomavirus combined with cytology and margin status identifies patients at risk for recurrence after conization for high-grade cervical intraepithelial neoplasia. Eur J Gynaecol Oncol. 2015;36(3):245-51.

14. Dos Santos Melli PP, Duarte G, Quintana SM. Multivariate analysis of risk factors for the persistence of high-grade squamous intraepithelial lesions following loop electrosurgical excision procedure. Int J Gynaecol Obstet. 2016;133(2):234-7. https://doi.org/10.1016/j.jpgo.2015.09.020.

15. Bilibio JP, Monego HI, Binda MLA, Dos Reis R. Menopausal status is associated with a high risk for residual disease after cervical conization with positive margins. PLoS ONE. 2019;14(6):e0217562. https://doi.org/10. 1371/journal.pone.0217562.

16. Montanari E, Grimm C, Schwameis R, Kuessel L, Polterauer S, Paternostro $\mathrm{C}$, Husslein $\mathrm{H}$. Influence of training level on cervical cone size and resection margin status at conization: a retrospective study. Arch Gynecol Obstet. 2018;297(6):1517-23. https://doi.org/10.1007/s00404-018-4761-1.

17. Ryu A, Nam K, Kwak J, Kim J, Jeon S. Early human papillomavirus testing predicts residual/recurrent disease after LEEP. J Gynecol Oncol. 2012;23(4):217-25. https://doi.org/10.3802/jgo.2012.23.4.217.

18. Ayhan A, Boynukalin FK, Guven S, Dogan NU, Esinler I, Usubutun A. Repeat LEEP conization in patients with cervical intraepithelial neoplasia grade 3 and positive ectocervical margins. Int J Gynaecol Obstet. 2009;105(1):14-7. https://doi.org/10.1016/j.ijgo.2008.11.015.

19. Wentzensen N. Epidemiologie, Prävention und Früherkennung des Zervixkarzinoms [Epidemiology, prevention and early detection of cervical cancer]. Onkologe (Berl). 2016;22(10):725-36. https://doi.org/10.1007/ s00761-016-0092-7.

20. Tasci T, Turan T, Ureyen I, Karalok A, Kalyoncu R, Boran N, Tulunay G. Is there any predictor for residual disease after cervical conization with positive surgical margins for HSIL or microinvasive cervical cancer? J Low Genit Tract Dis. 2015;19(2):115-8. https://doi.org/10.1097/LGT.00000 00000000079.

21. Kang WD, Ju UC, Kim SM. A human papillomavirus (HPV)-16 or HPV-18 genotype is a reliable predictor of residual disease in a subsequent hysterectomy following a loop electrosurgical excision procedure for cervical intraepithelial neoplasia 3. J Gynecol Oncol. 2016;27(1):e2. https://doi. org/10.3802/jgo.2016.27.e2.

22. Nam K, Kwak J, Kim J, Jeon S. Human papillomavirus type 16 causes larger colposcopic lesions than other HPV types in patients with grade 3 cervical intraepithelial neoplasia. J Low Genit Tract Dis. 2013:17(1):1-5. https:// doi.org/10.1097/LGT.0b013e31825afd5b.

23. Diaz ES, Aoyama C, Baquing MA, Beavis A, Silva E, Holschneider C, Cass I. Predictors of residual carcinoma or carcinoma-in-situ at hysterectomy following cervical conization with positive margins. Gynecol Oncol. 2014;132(1):76-80. https://doi.org/10.1016/j.ygyno.2013.11.019.

24. Kim HJ, Kim KR, Mok JE, Nam JH, Kim YT, Kim YM, Kim JH, Yun SC. Pathologic risk factors for predicting residual disease in subsequent hysterectomy following LEEP conization. Gynecol Oncol. 2007;105(2):434-8. https://doi.org/10.1016/j.ygyno.2006.12.036.

25. Xiao YP, Tao X, Zhao CY, Qu YQ, Xie F, Ning Y. Relationship between various histological status of margins of LEEP and residual HSIL or worse 
at hysterectomy following conization. Zhonghua Fu Chan Ke Za Zhi. 2019;54(1):19-23. https://doi.org/10.3760/cma.j.issn.0529-567x.2019.01. 005 (in Chinese).

26. Fernández-Montolí ME, Tous S, Medina G, Castellarnau M, García-Tejedor A, de Sanjosé S. Long-term predictors of residual or recurrent cervical intraepithelial neoplasia 2-3 after treatment with a large loop excision of the transformation zone: a retrospective study. BJOG. 2020;127(3):377-87. https://doi.org/10.1111/1471-0528.15996.

27. Sarian LO, Derchain SF, Andrade LA, Tambascia J, Morais SS, Syriänen KJ. HPV DNA test and Pap smear in detection of residual and recurrent disease following loop electrosurgical excision procedure of high-grade cervical intraepithelial neoplasia. Gynecol Oncol. 2004;94(1):181-6. https://doi.org/10.1016/j.ygyno.2004.03.036.

28. Valenti G, Vitale SG, Tropea A, Biondi A, Laganà AS. Tumor markers of uterine cervical cancer: a new scenario to guide surgical practice? Updates Surg. 2017;69(4):441-9. https://doi.org/10.1007/s13304-017-0491-3.
29. Rossetti D, Vitale SG, Tropea A, Biondi A, Laganà AS. New procedures for the identification of sentinel lymph node: shaping the horizon of future management in early stage uterine cervical cancer. Updates Surg. 2017;69(3):383-8. https://doi.org/10.1007/s13304-017-0456-6.

30. Abdelaal AM, Attalla EM, Elshemey WM. Estimation of out-of-field dose variation using markus ionization chamber detector. SciMed J. 2020;2(1):8-15. https://doi.org/10.28991/SciMedJ-2020-0201-2.

\section{Publisher's Note}

Springer Nature remains neutral with regard to jurisdictional claims in published maps and institutional affiliations.
Ready to submit your research? Choose BMC and benefit from:

- fast, convenient online submission

- thorough peer review by experienced researchers in your field

- rapid publication on acceptance

- support for research data, including large and complex data types

- gold Open Access which fosters wider collaboration and increased citations

- maximum visibility for your research: over $100 \mathrm{M}$ website views per year

At BMC, research is always in progress.

Learn more biomedcentral.com/submissions 